\title{
NRAMP1- or cytokine-induced bacteriostasis of Mycobacterium avium by mouse macrophages is independent of the respiratory burst
}

\author{
M. Salomé Gomes and Rui Appelberg
}

Laboratory of Microbiology and Immunology of Infection, Institute for Molecular and Cell Biology, University of Porto, Rua do Campo Alegre, 823, 4150-180 Porto, Portugal
Author for correspondence: M. Salomé Gomes. Tel: +351 226074900. Fax: + 351226099157. e-mail: sgomes@ibmc.up.pt

\begin{abstract}
Restriction of the growth of Mycobacterium avium was studied in wild-type and p47 phox-deficient macrophages. The ability of gamma interferon and tumour necrosis factor alpha to induce antimycobacterial activity in bonemarrow-derived macrophages or the expression of the NRAMP1-mediated resistance to $M$. avium were not affected by the deficiency in $\mathrm{p} 47^{\text {phox }}$. The addition of exogenous iron increased mycobacterial growth in macrophages expressing a functional NRAMP1 protein or a mutant NRAMP1 protein. Reactive oxygen species are therefore not involved in the constitutive or induced anti$M$. avium activities of the mouse macrophage.
\end{abstract}

Keywords: iron, antimicrobial, innate immunity

\section{INTRODUCTION}

Mycobacterium avium is a facultative intracellular pathogen that survives and proliferates inside the macrophages of susceptible hosts (Frehel et al., 1991). The capacity to grow inside macrophages implies that $M$. avium must be capable of either avoiding the activation of some of its antimicrobial mechanisms or resisting their consequences. One of the ways by which M. avium can avoid destruction inside macrophages is by inhibiting the production of superoxide. In fact, the production of superoxide by macrophages upon phagocytosis of M. avium is usually low (Bermudez \& Young, 1989). Also, the production of higher levels of oxygen radicals was associated with strains of the mycobacterium with lower virulence (Bermudez \& Young, 1989; Gangadharam \& Edwards, 1984; Sarmento \& Appelberg, 1996). Nevertheless, macrophages can be activated to produce increased amounts of superoxide by treatment with IFN- $\gamma$ (gamma interferon) and/or TNF- $\alpha$ (tumour necrosis factor $\alpha$ ), treatments which concomitantly cause $M$. avium growth restriction (Sarmento \& Appelberg, 1996; Appelberg et al., 1992). Previous studies using scavengers of reactive oxygen species indicated that the production of superoxide was not necessary for growth restriction of the most virulent strains of $M$. avium, but could play a role in the control

Abbreviations: $\mathrm{BMM} \varphi$, bone-marrow-derived macrophages; IFN- $\gamma_{\text {, }}$ gamma interferon; SmD, smooth domed; SmT, smooth transparent; TNF- $\alpha$, tumour necrosis factor $\alpha$. of less virulent strains (Sarmento \& Appelberg, 1996; Appelberg \& Orme, 1993). The interpretation of these results is made difficult by the lack of understanding about the capacity of these scavenging compounds to reach the $M$. avium-containing phagosomes and the fact that other molecules such as peroxidases or iron may modulate the effectiveness of the antimicrobial action of reactive oxygen species. In this context, it has been proposed that NRAMP1, a putative cation transporter expressed in the membranes of late endosomes, lysosomes and phagosomes, namely those containing $M$. avium inside macrophages (Gruenheid et al., 1997; Searle et al., 1998), transports iron into the bacteriumcontaining phagosome and causes bacterial killing via the induction of toxic reactive oxygen species (Kuhn et al., 1999; Zwilling et al., 1999). Additionally, it has been reported that mouse macrophages expressing the $\mathrm{R}$ allele of the Nramp1 gene can produce more superoxide than those expressing the $S$ allele of the same gene (Denis et al., 1988), which could suggest a role for reactive oxygen species in the NRAMP1-mediated mycobacteriostasis. On the other hand, we have proposed an opposite view in that NRAMP1 pumps iron out of the phagosome, thus depriving the micro-organism of this nutrient (Gomes \& Appelberg, 1998) rather than influencing the generation of Fenton-derived hydroxyl radicals. This hypothesis is also supported by the data obtained by Jabado et al. (2000).

It is now possible to readdress these questions using mice that were rendered deficient in one of the components of the NADPH oxidase, p47 ${ }^{\text {phox }}$ (Jackson et al., 
1995). Segal et al. (1999) have infected these mice with M. avium and saw no differences in susceptibility when compared to wild-type mice. However, only one strain of M. avium was used, and the studies were performed in vivo. In the present work, we expanded these experiments to include different strains of M. avium, with different virulences, and we performed the experiments with isolated macrophages so as to address the role of superoxide production in the interaction of macrophages with $M$. avium, in the absence of additional effects on other components of the immune response. Overall, our results indicate that the production of superoxide through the NADPH oxidase is not necessary either for cytokine or NRAMP1-mediated growth restriction of $M$. avium inside mouse bonemarrow-derived macrophages $(\operatorname{BMM} \varphi)$.

\section{METHODS}

Bacteria. Mycobacterium avium strain 25291, smooth transparent $(\mathrm{SmT})$ variant, was obtained from the American Type Culture Collection (Manassas, VA). Strains 2447 SmT and 2151 smooth domed ( $\mathrm{SmD}$; opaque) were isolated from AIDS patients and given to us by F. Portaels, Institute of Tropical Medicine, Antwerp, Belgium and J. Belisle, Colorado State University, USA, respectively. Strain $1983 \mathrm{SmT}$ was isolated from an HIV-negative patient.

All mycobacteria were grown in Middlebrook $7 \mathrm{H} 9$ Broth (Difco) with 0.04\% Tween 80 (Sigma). Cultures were harvested during exponential phase, centrifuged, washed in saline with Tween 80, briefly sonicated and stored in aliquots at $-70{ }^{\circ} \mathrm{C}$ until used.

Animals. p $47^{\text {phox }}$-deficient mice were bred at the IBMC (Instituto de Biologia Molecular e Cellular) facilities from breeding pairs kindly provided by Drs Steven Holland and Braham Segal, from the National Institutes of Health, Bethesda, MD, USA (Jackson et al., 1995). These mice were kept in HEPA (high efficiency particulate air)-filter-bearing cages and fed sterilized food and water. Mice were initially genotyped for the Nramp1 allele and found to be heterozygous for the R (G169) and S (D169) alleles. Breeders were subsequently selected for homozygosity of either the R or the $S$ allele and progeny were used in accordance to their Nramp1 genotype as indicated in the text below.

C57Bl/6 mice $\left(\mathrm{Nramp}^{\mathrm{s}}\right)$ were purchased from the Gulbenkian Institute (Oeiras, Portugal) and $129 \mathrm{~Sv}$ mice $\left(\mathrm{Nramp}^{\mathrm{r}}\right)$ were bred in our facilities. These strains correspond to the parent strains used in the generation of the $\mathrm{p} 47^{\mathrm{phox}}$ gene-disrupted mice. The wild-type mice were kept under standard hygiene conditions.

Genomic PCR analysis of the Nramp1 gene. Genomic DNA samples were obtained from each mouse by treating a portion of the ear with proteinase K (Sigma). The amplification of the Nramp1 gene was performed using Taq DNA polymerase (Gibco) and primers specific for the Nramp1 gene, one oligonucleotide being common to both alleles and the other being specific for either $\mathrm{R}$ or $\mathrm{S}$ allele, as described elsewhere (Gomes et al., 1999). The amplification was done in a Gene Amp PCR System 9600 (Perkin-Elmer-Roche).

Infection of BMM $\boldsymbol{\varphi}$. Macrophages were derived from mouse bone marrow as follows. Each femur was flushed with $5 \mathrm{ml}$ of Hank's Balanced Salt Solution (HBSS). The resulting cell suspension was centrifuged and the cells resuspended in Dulbecco's Modified Eagle's Medium (DMEM, Gibco) containing $10 \%$ Foetal Bovine Serum (FBS, Gibco) and 10\% L929 Cell Conditioned Medium (LCCM), as a source of Macrophage-Colony Stimulating Factor (M-CSF). The cells were distributed in 24 -well plates and incubated at $37^{\circ} \mathrm{C}$ in a $7 \%$ $\mathrm{CO}_{2}$ atmosphere. Three days after seeding, another $0.1 \mathrm{ml}$ LCCM was added. On the 7 th day, the medium was renewed.

On the 10th day of culture, when cells were completely differentiated into macrophages, they were infected with $M$. avium. About $10^{6}$ c.f.u. M. avium were added to each well (approximately 10 bacteria per macrophage), in $0.2 \mathrm{ml}$ DMEM. Cells were incubated for $4 \mathrm{~h}$ at $37^{\circ} \mathrm{C}$ in a $\mathrm{CO}_{2}$ atmosphere and then washed with warm HBSS to remove non-internalized bacteria and reincubated in DMEM, with $10 \%$ FBS and 10\% LCCM. In some of the wells, the macrophages were immediately lysed and the number of viable intracellular bacteria counted as described below (time zero). The other cells were incubated for 7 days to measure the intracellular growth of the bacteria.

The measurement of mycobacterial growth was done by counting c.f.u.s. Briefly, at different time points after infection, the cells were lysed by adding $0 \cdot 1 \%$ saponin to each well. The resulting bacterial suspension was serially diluted 1:10 in water containing $0 \cdot 04 \%$ Tween 80 . The dilutions were plated on Middlebrook 7H10 agar (Difco) and the number of colonies counted 8 to 10 days later. For each condition tested, three culture wells were used. The results presented correspond to the mean and standard deviation of these three wells.

Macrophage treatments. Recombinant murine IFN- $\gamma$ (Gibco), $100 \mathrm{U}$ per culture well and recombinant murine TNF- $\alpha$ (Genzyme), $50 \mathrm{U}$ per culture well, were added daily to the cultures, starting immediately after infection and until day 4 .

Ferric ammonium citrate or ferrous sulfate (both from Merck) were added to the culture medium immediately after infection, at final concentrations of $0 \cdot 01 \mu \mathrm{M}$ or $1 \mu \mathrm{M}$ iron.

\section{RESULTS}

\section{Growth of different strains of $M$. avium inside murine BMM $\varphi$; effect of IFN- $\gamma$ and TNF- $\alpha$}

To evaluate the role played by superoxide production in the growth restriction of $M$. avium inside murine macrophages, we used $\mathrm{BMM} \phi$ from mice that do not express the p47 component of the phagocyte oxidase $\left(\mathrm{p} 47^{\text {phox- }- \text { - }}\right)$ and infected them with one of four different strains of $M$. avium, as described in Methods. The infected macrophages were then cultured in medium alone or were treated with $100 \mathrm{U}$ IFN- $\gamma$ or $50 \mathrm{U}$ TNF- $\alpha$ per culture well per day, both singly and in combination, during the first 4 days of infection. At different time points after infection, the cells were lysed and the number of bacteria quantified as c.f.u. in agar medium. As $\mathrm{p} 47^{\text {phox }}$-expressing macrophage controls, we used $\mathrm{BMM} \phi$ from either $129 \mathrm{~Sv}$ or $\mathrm{C} 57 \mathrm{Bl} / 6$ mice, according to the Nramp1 allele expressed by the $4^{\text {phox- } / \text { macro- }}$ phages, as determined by genomic PCR analysis. Either IFN- $\gamma$ or TNF- $\alpha$ given alone caused growth inhibition of all four strains of $M$. avium tested in both types of macrophages $\left(\mathrm{p} 47^{\text {phox }+/+}\right.$ or $\left.\mathrm{p} 47^{\mathrm{phox}-/ /}\right)$. The combination of the two cytokines was the most efficient stimulus, inducing mycobacteriostasis of the most viru- 


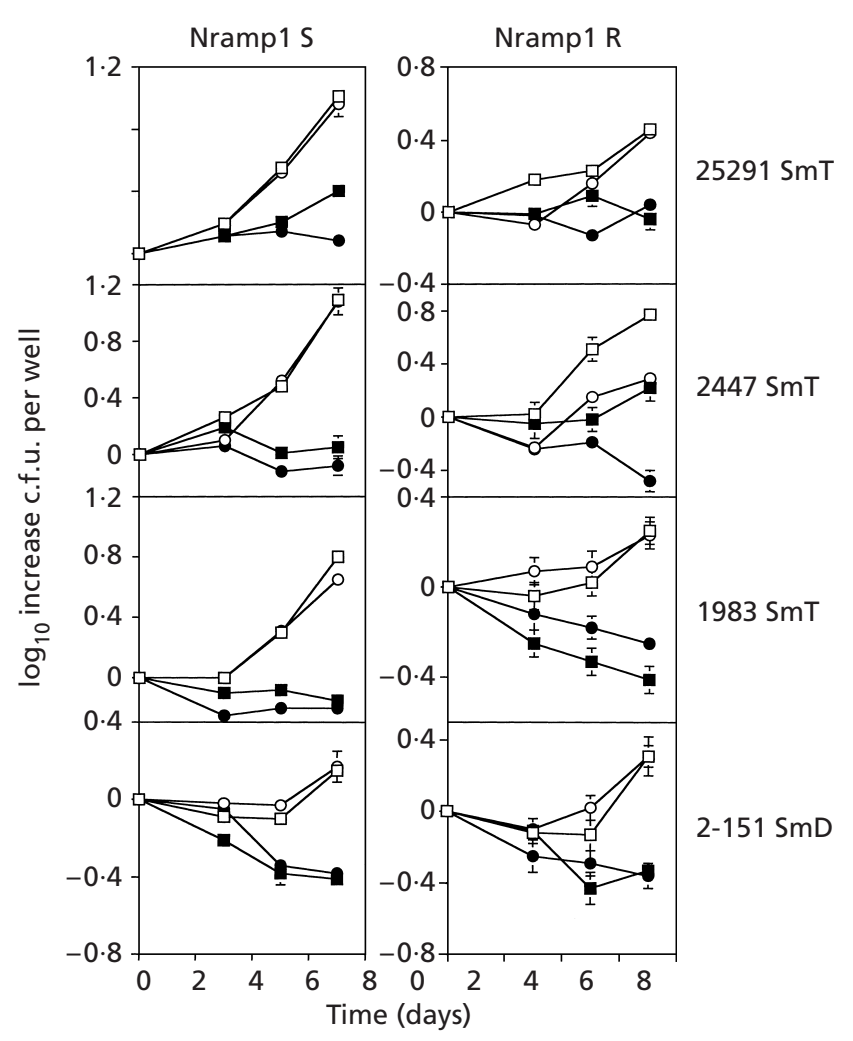

Fig. 1. Effect of IFN- $\gamma$ and TNF- $\alpha$ treatment on the growth kinetics of different $M$. avium strains inside $p 47^{\text {phox }}$-deficient and control $\operatorname{BMM} \varphi . \operatorname{BMM} \varphi$ were obtained from $\mathrm{p} 47^{\text {phox-l- }}$ mice (circles) expressing either the $\mathrm{S}$ or the $\mathrm{R}$ allele of the Nramp1 gene or from C57BI/6 (p47 phox $\left.+1+^{+}, N r a m p 1^{5}\right)$ or 129Sv (p47 ${ }^{\text {phox }+1+}$, Nramp 1') control mice (squares). Macrophages were infected with $10^{6}$ c.f.u. per well of each of the $M$. avium strains shown (25291 SmT, $2447 \mathrm{SmT}, 1983 \mathrm{SmT}$ and 2-151 SmD) and were either left untreated (white symbols) or were treated daily with $100 \mathrm{U}$ recombinant murine IFN- $\gamma \mathrm{ml}^{-1}$ plus $50 \mathrm{U}$ recombinant murine TNF- $\alpha \mathrm{ml}^{-1}$ until day 4 of infection (black symbols). The graph shows the mean \pm one standard deviation of the $\log _{10}$ increase in c.f.u. per well obtained from three wells for each condition. Each of the experiments was done at least twice. One representative experiment is shown.

lent strains and bacterial killing of the least virulent of the four strains, 2-151 SmD. In Fig. 1, we show the kinetics of growth of the four M. avium strains tested inside $\mathrm{C} 57 \mathrm{Bl} / 6$ or $\mathrm{p} 47^{\mathrm{phox}-/-}$ macrophages expressing the $\mathrm{S}$ allele of Nramp1, and the effect of IFN- $\gamma$ plus TNF- $\alpha$ on mycobacterial proliferation. It is clear from these data that the absence of a functional phagocyte oxidase did not increase the permissiveness of murine $\operatorname{BMM} \varphi$ to M. avium, even of the low virulence strains, like 1983 SmT or 2-151 SmD. Moreover, phagocyte oxidasedeficient macrophages were equally capable of inhibiting the growth or even killing $M$. avium upon stimulation with IFN- $\gamma$ plus TNF- $\alpha$. Similar results were obtained using $\mathrm{p} 47^{\text {phox }-/-}$ macrophages expressing the $\mathrm{R}$ allele of Nramp1, in parallel with macrophages derived from $129 \mathrm{~Sv}$ mice (Fig. 1). Superoxide production was measured as phorbol myristate acetate-stimulated cytochrome $c$ reduction. The combination of IFN- $\gamma$ and
TNF- $\alpha$ induced the production of superoxide in wildtype macrophages (in higher amounts in 129Sv than in C57Bl/6 macrophages), while this production could not be detected in $\mathrm{p} 47^{\text {phox }-/}$ macrophages (data not shown).

\section{Role of superoxide production on the NRAMP1 protein induced growth restriction}

It has been proposed that NRAMP1 transports iron into the bacterium-containing phagosome and causes bacterial killing via the Fenton catalysis of toxic reactive oxygen species (Goswami et al., 2001; Kuhn et al., 1999; Zwilling et al., 1999). This hypothesis implies that the growth restriction activity of NRAMP1 is dependent on, or at least highly favoured by, the presence of a functional phagocyte oxidase in the phagosomal membrane, as a source of superoxide. To challenge this hypothesis and since we had $\mathrm{p} 47^{\text {phox-/- }}$ littermates expressing either the $N \operatorname{ram} p 1^{\mathrm{r}}$ or $\mathrm{S}$ alleles, we compared the growth of $M$. avium inside these different types of macrophages. As shown in Fig. 1, macrophages from Nramp $1^{\mathrm{r}}$ mice were consistently more effective at controlling the proliferation of virulent strains than macrophages from $N r a m p 1^{\mathrm{s}}$ mice. No expression of this phenotype was observed with the non-virulent 2-151 SmD strain. The deficiency in the phagocyte oxidase did not reduce the ability of macrophages from Nramp $1^{\mathrm{r}}$ mice to control the growth of M. avium and indeed in some experiments, such as the case here with strain 2447 SmT, some improvement in the anti-mycobacterial activity of these macrophages was observed upon disruption of $\mathrm{p} 47^{\text {phox }}$. These results strongly suggest that NRAMP1-mediated growth restriction does not involve the production of oxygen radicals.

\section{Effect of iron on the intramacrophagic growth of $M$. avium}

As said previously, some authors claim that NRAMP1 pumps iron into the phagosome and that contributes to M. avium killing through generation of hydroxyl radicals. We tested the effects of iron addition to macrophages infected with M. avium and whether those effects were dependent on the presence of a functional NADPH oxidase. As shown in Fig. 2, the addition of iron caused an increase in the intra-macrophagic growth of $M$. avium, rather than inhibition. As expected, the same stimulatory effect was seen in macrophages lacking either a functional phagocyte oxidase or a functional NRAMP1 protein. Similar results were also obtained when ferrous sulfate was used as the source of iron.

\section{DISCUSSION}

Strains of $M$. avium differ widely in their virulence as assessed by the capacity to grow in mice or mousederived macrophages (Pedrosa et al., 1994). One of the factors suggested to be involved in these differences is the capacity to inhibit the induction of superoxide production during phagocytosis and/or the resistance to superoxide and other reactive oxygen species (Sarmento 


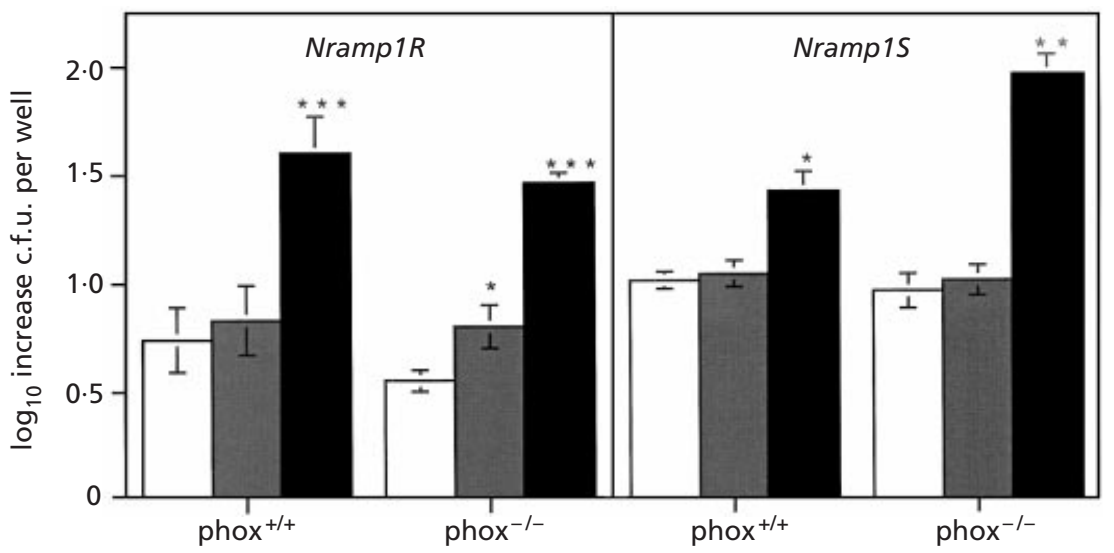

Fig. 2. Effect of the addition of ferric ammonium citrate on the growth of $M$. avium $25291 \mathrm{SmT}$ inside $\mathrm{BMM} \varphi$. In two independent experiments, macrophages expressing either the $R$ or the $S$ allele and mutated or not for the p47 ${ }^{\text {phox }}$ gene were infected and treated with 0.01 (grey bars) or 1.0 (black bars) $\mu \mathrm{M}$ iron in addition to the amount normally present in the culture medium, or with no additional iron supplement (white bars). The graph shows the mean \pm one standard deviation of the $\log _{10}$ increase in c.f.u. per well obtained from three wells for each condition. Statistical analysis was performed using Student's $t$-test and results are shown as *,P<0.05; **,P<0.01; ***,P<0.001.

\& Appelberg, 1996). In the present work, we studied four M. avium strains, covering a wide spectrum of virulence, to readdress the question of the importance of reactive oxygen species production for the macrophage resistance against $M$. avium, using a new tool, $\mathrm{p} 47^{\text {phox }- \text { - }}$ mice. These mice fail to respond with a respiratory burst when appropriately triggered, e.g. with phorbol esters or particles (Jackson et al., 1995 and our unpublished observations). Despite this enzymic deficiency in an antimicrobial pathway, macrophages from the $\mathrm{p} 47^{\text {phox }-/-}$ mice were able to respond to IFN- $\gamma$ and TNF- $\alpha$ by decreasing the growth of all the M. avium strains tested. In the case of the least virulent strain, 2-151 SmD, the cytokine treatment led to bacterial killing. The degree of growth restriction or killing was the same as was observed with wild-type macrophages of similar genetic background. In the case of strain 2-151 SmD, the lack of a functional NADPH oxidase did not lead to an increase in bacterial growth, showing that the lack of virulence is not explained by susceptibility to reactive oxygen species.

Since we have already shown that M. avium is resistant to macrophage-generated nitric oxide (Gomes et al., 1999), the present data show that mouse macrophages must have oxygen and nitrogen reactive species-independent mechanisms that are activated by IFN- $\gamma$ and TNF- $\alpha$ and cause the bacteriostasis or killing of this opportunistic pathogen. The mechanisms involved in the resistance of pathogenic mycobacteria to macrophage-generated reactive oxygen species are not completely elucidated. There is no functional OxyR system in Mycobacterium tuberculosis (Sherman et al., 1995) although the expression of catalase-peroxidase correlates with resistance against hydrogen peroxide (Manca et al., 1999). Also, the presence of cyclopropanated mycolic acids seems to be important for resistance against hydrogen peroxide, since the trans- formation of Mycobacterium smegmatis with a gene involved in the biosynthesis of these molecules renders the bacterium more resistant to hydrogen peroxide (Yuan et al., 1995). However, M. avium is more resistant to hydrogen peroxide than M. tuberculosis (Gangadharam \& Pratt, 1984), suggesting that the former mycobacterial species may have additional scavenger mechanisms to deal with oxidative stress.

Unlike M. tuberculosis, however, M. avium proliferation in vivo in mice is under the control of the Nramp1 gene (Appelberg \& Sarmento, 1990; Medina et al., 1996). NRAMP1 is a transmembrane protein expressed in endosomal and phagosomal membranes of macrophages, that contributes to inhibition of growth of several intracellular pathogens, including $\mathrm{Myco-}$ bacterium bovis, M. avium, Leishmania donovani and Salmonella typhimurium (Gruenheid \& Gros, 2000). Two alleles of the Nramp1 gene occur naturally in laboratory mouse strains. Only the wild-type or R allele encodes a functional protein, while the $S$ allele is presumably not expressed or encodes a non-functional protein (Gruenheid \& Gros, 2000). NRAMP1 mediates pleiotropic effects, ranging from major histocompatibility complex expression to superoxide production or phagosome acidification (Gruenheid et al., 1997; Denis et al., 1988; Hackam et al., 1998). It is not clear how these effects contribute to the growth restriction of intracellular pathogens. A large number of genes with high homology to Nramp1 have been recently characterized, both from mammals and from microorganisms (Gruenheid \& Gros, 2000). These proteins seem to be implicated in divalent cation transport, namely $\mathrm{Fe}^{2+}$ and $\mathrm{Mn}^{2+}$ (Gruenheid \& Gros, 2000; Jabado et al., 2000). We have previously reported data supporting the hypothesis that the mycobacteriostatic action of NRAMP1 is due to iron-depletion of the pathogen-containing phagosome (Gomes \& Appelberg, 
1998). Other authors claim that NRAMP1 transports iron from the cytosol into the pathogen-containing phagosome and that this would contribute to bacterial killing by stimulating the production of hydroxyl radicals from less toxic reactive oxygen species, namely superoxide and hydrogen peroxide (Goswami et al., 2001; Kuhn et al., 1999; Zwilling et al., 1999). If the bacteriostatic activity of NRAMP1 were to be due to hydroxyl formation, then it would be hampered in macrophages lacking NADPH oxidase, the enzyme responsible for the production of superoxide. The data presented here show that this is not the case. The Nramp1-mediated resistance was not affected by the mutation induced in the oxidase system as the addition of exogenous iron to macrophages expressing a functional NRAMP1 protein blocked antimicrobial activity instead of promoting it as the previous hypothesis would have predicted. In some experiments, the deficiency in the phagocyte oxidase was even able to increase the antimicrobial activity of macrophages expressing the functional NRAMP1 molecule although the mechanism involved was not investigated here.

In summary, our data show that restriction of growth of $M$. avium by macrophages is independent of the generation of reactive oxygen species through the respiratory burst NADPH oxidase. This is true for the antimycobacterial mechanisms induced by macrophageactivating cytokines such as IFN- $\gamma$ and TNF- $\alpha$ as well as for the constitutive antimycobacterial mechanism mediated by the NRAMP1 protein.

\section{ACKNOWLEDGEMENTS}

We thank Drs Steven Holland and Braham Segal for their gift of breeding pairs of $\mathrm{p} 47^{\text {phox }}$-deficient mice.

This work was supported by contract 13232/1998 from the PRAXIS XXI programme.

\section{REFERENCES}

Appelberg, R. \& Orme, I. M. (1993). Effector mechanisms involved in cytokine-mediated bacteriostasis of Mycobacterium avium infections in murine macrophages. Immunology 80, 352-359.

Appelberg, R. \& Sarmento, A. M. (1990). The role of macrophage activation and of $B c g$-encoded macrophage function(s) in the control of Mycobacterium avium infection in mice. Clin Exp Immunol 80, 324-331.

Appelberg, R., Orme, I. M., Pinto de Sousa, M. I. \& Silva, M. T. (1992). In vitro effects of interleukin-4 on interferon- $\gamma$-induced macrophage activation. Immunology 76, 553-559.

Bermudez, L. E. M. \& Young, L. S. (1989). Oxidative and nonoxidative intracellular killing of Mycobacterium avium complex. Microb Pathog 7, 289-298.

Denis, M., Forget, A., Pelletier, M. \& Skamene, E. (1988). Pleiotropic effects of the $\mathrm{Bcg}$ gene. III. Respiratory burst in $\mathrm{Bcg}$ congenic macrophages. Clin Exp Immunol 73, 370-375.

Frehel, C., de Chastellier, C., Offredo, C. \& Berche, P. (1991). Intramacrophagic growth of Mycobacterium avium during infection of mice. Infect Immun 59, 2207-2214.

Gangadharam, P. R. J. \& Edwards, C. K., III (1984). Release of superoxide anion from resident and activated mouse peritoneal macrophages infected with Mycobacterium intracellulare. Am Rev Respir Dis 130, 834-838.

Gangadharam, P. R. J. \& Pratt, P. F. (1984). Susceptibility of Mycobacterium intracellulare to hydrogen peroxide. Am Rev Respir Dis 130, 309-311.

Gomes, M. S. \& Appelberg, R. (1998). Evidence for a link between iron metabolism and Nramp1 gene function in innate resistance against Mycobacterium avium. Immunology 95, 165-168.

Gomes, M. S., Flórido, M., Pais, T. F. \& Appelberg, R. (1999). Improved clearance of Mycobacterium avium upon disruption of the inducible nitric oxide synthase gene. J Immunol 162, 6734-6739.

Goswami, T., Bhattacharjee, A., Babal, P., Searle, S., Moore, E., Li, M. \& Blackwell, J. M. (2001). Natural-resistance-associated macrophage protein 1 is an $\mathrm{H}^{+}$/bivalent cation antiporter. Biochem $\mathrm{J}$ 354, 511-519.

Gruenheid, S. \& Gros, P. (2000). Genetic susceptibility to intracellular infections: Nramp1, macrophage function and divalent cations transport. Curr Opin Microbiol 3, 43-48.

Gruenheid, S., Pinner, E., Desjardins, M. \& Gros, P. (1997). Natural resistance to infection with intracellular pathogens: the Nramp1 protein is recruited to the membrane of the phagosome. J Exp Med 185, 717-730.

Hackam, D. J., Rotstein, O. D., Zhang, W., Gruenheid, S., Gros, P. \& Grinstein, S. (1998). Host resistance to intracellular infection: mutation of natural resistance-associated macrophage protein 1 (Nramp1) impairs phagosomal acidification. J Exp Med 188, 351-364.

Jabado, N., Jankowski, A., Gougaparsad, S., Picard, V., Grinstein, S. \& Gros, P. (2000). Natural resistance to intracellular infections - natural resistance-associated macrophage protein 1 (Nramp1) functions as a pH-dependent manganese transporter at the phagosomal membrane. J Exp Med 192, 1237-1248.

Jackson, S. H., Gallin, J. I. \& Holland, S. M. (1995). The $\mathrm{p} 47^{\text {phox- }-1}$ mouse knock-out model of chronic granulomatous disease. J Exp Med 182, 751-758.

Kuhn, D. E., Baker, B. D., Lafuse, W. P. \& Zwilling, B. S. (1999). Differential iron transport into phagosomes isolated from the RAW264.7 macrophage cell lines transfected with Nramp1 $1^{\text {Gly169 }}$

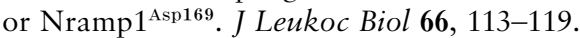

Manca, C., Paul, S., Barry, C. E., III, Freedman, V. H. \& Kaplan, G. (1999). Mycobacterium tuberculosis catalase and peroxidase activities and resistance to oxidative killing in human monocytes in vitro. Infect Immun 67, 74-79.

Medina, E., Rogerson, B. J. \& North, R. J. (1996). The Nramp1 antimicrobial resistance gene segregates independently of resistance to virulent Mycobacterium tuberculosis. Immunology $\mathbf{8 8}$, 479.

Pedrosa, J., Flórido, M., Kunze, Z. M., Castro, A. G., Portaels, F., McFadden, J. J., Silva, M. T. \& Appelberg, R. (1994). Characterization of the virulence of Mycobacterium avium complex isolates in mice. Clin Exp Immunol 98, 210-216.

Sarmento, A. M. \& Appelberg, R. (1996). Involvement of reactive oxygen intermediates in the tumor necrosis factor-dependent bacteriostasis of Mycobacterium avium. Infect Immun 64, 32243230.

Searle, S., Bright, N. A., Roach, T. I. A., Atkinson, P. G. P., Barton, C. H., Meloen, R. H. \& Blackwell, J. M. (1998). Localisation of Nramp1 in macrophages: modulation with activation and infection. J Cell Sci 111, 2855-2866.

Segal, B. H., Doherty, T. M., Wynn, T. A., Cheever, A. W., Sher, A. 
\& Holland, S. M. (1999). The $\mathrm{p} 47^{\mathrm{phox}-\digamma}$ mouse model of chronic granulomatous disease has normal granuloma formation and cytokine responses to Mycobacterium avium and Schistosoma mansoni eggs. Infect Immun 67, 1659-1665.

Sherman, D. R., Sabo, P. J., Hickey, M. J., Arain, T. M., Mahairas, G. G., Yuan, Y., Barry, C. E., III \& Stover, C. K. (1995). Disparate responses to oxidative stress in saprophytic and pathogenic mycobacteria. Proc Natl Acad Sci US A 92, 6625-6629.

Yuan, Y., Lee, R. E., Besra, G. S., Belisle, J. T. \& Barry, C. E., III
(1995). Identification of a gene involved in the biosynthesis of cyclopropanated mycolic acids in Mycobacterium tuberculosis. Proc Natl Acad Sci US A 92, 6630-6634.

Zwilling, B. S., Kuhn, D. E., Wikoff, L., Brown, D. \& Lafuse, W. (1999). Role of iron in Nramp1-mediated inhibition of mycobacterial growth. Infect Immun 67, 1386-1392.

Received 4 March 2002; revised 10 May 2002; accepted 14 May 2002. 